\title{
Fixed Point Theorems for $(\psi, \alpha)$ Type Expansive Mappings in b-Metric Spaces
}

\section{A. S. Saluja}

Institute for Excellence in Higher Education, Bhopal, Madhya Pradesh, India.

\begin{tabular}{ll}
\hline ARTICLE INFO & ABSTRACT \\
\hline 05 February 2022 & $\begin{array}{l}\text { In this paper, we confine over selves to obtain some results on fixed point theorems for a new } \\
\text { category of expansive mappings called }(\psi, \alpha) \text { expansive mapping in b- metric spaces. Our results } \\
\text { are with much shorter proof and generalize many existing results in the literature. We also have } \\
\text { given some examples to support our results. }\end{array}$ \\
$\begin{array}{l}\text { Corresponding Author: } \\
\text { A.S.Saluja }\end{array}$ & P.S.
\end{tabular}

KEYWORDS: Fixed Point, Expansive Mappings, b- Metric Space etc.

Mathematical Subject Classification (2000): Primary 47H10, Secondary 54H25.

\section{INTRODUCTION}

During the last 95- years a lot of fixed point theorems have been established and we find that Banach contraction principle is at the base of the most of these results established so far. The concept of metric spaces has been generalized in many directions. The notion of a b-metric space was introduced by Czerwik in $[11,12]$ and during the last few years by many authors a lot of fixed point theorems have been proved in b-metric spaces. Recently, Samet et. al.[30] studied a new class of $(\alpha, \psi)$ type contraction and $\alpha$ - admissible mapping

The following definitions are required in sequel.

\section{PRELIMINARIES}

Definition 2.1 ([6]) Let $X$ be a nonempty set. A mapping $d$ : $\mathrm{X} \times \mathrm{X} \rightarrow[0, \infty)$ is called $\mathrm{b}$-metric if there exists a real number $\mathrm{b} \geq 1$ such that for every $\mathrm{x}, \mathrm{y}, \mathrm{z} \in \mathrm{X}$, we have

(i) $\quad d(x, y)=0$ if and only if $x=y$

(ii) $\quad \mathrm{d}(\mathrm{x}, \mathrm{y})=\mathrm{d}(\mathrm{y}, \mathrm{x})$

(iii) $\mathrm{d}(\mathrm{x}, \mathrm{z}) \leq \mathrm{b}[\mathrm{d}(\mathrm{x}, \mathrm{y})+\mathrm{d}(\mathrm{y}, \mathrm{z})]$

In this case the pair $(X, d)$ is called a b-metric space. There exists many examples in the literature (see[6-8])(BS) showing that every metric function is a b-metric function with $\mathrm{b}=1$, while the converse is not true, i.e. the class $\mathrm{b}$ - metric is effectively larger than that of ordinary metric spaces.

Definition 2.2 [ 15] Let $\left\{x_{n}\right\}$ be a sequence in a b-metric space (X, d).

(i) $\left\{\boldsymbol{x}_{n}\right\}$ is called b-convergent if and only if there is $\mathrm{X} \in \mathrm{X}$ such that $\mathrm{d}\left(\boldsymbol{x}_{\boldsymbol{n}}, \boldsymbol{x}\right) \rightarrow 0$ as $\mathrm{n} \rightarrow \infty$.

(ii) $\quad\left\{\boldsymbol{x}_{\boldsymbol{n}}\right\}$ is called b-Cauchy sequence if and only if $\mathrm{d}\left(\boldsymbol{x}_{\boldsymbol{n}}, \boldsymbol{x}_{\boldsymbol{m}}\right) \rightarrow 0$ as $\mathrm{n}, \mathrm{m} \rightarrow \infty$.
A b-metric space is said to be complete if and only if each b-Cauchy sequence in this space is b-convergent.

Recently, Samet et al.[30] considered the following family of functions and presented the new notion of $(\alpha-\psi)$ contractive and $\alpha$-admissible mappings.

Definition 2.3 ([31]) Let $\varphi$ denote the family of all functions $\psi:[0, \infty) \rightarrow[0, \infty)$ which satisfy the following :

(i) $\quad \sum_{\mathbf{n}=\mathbf{1}}^{\infty} \psi^{\mathbf{n}}(\mathbf{t})<\infty$ for each $\mathrm{t}>0$, where $\psi^{\mathbf{n}}$ is the nth iterate of $\psi$;

(ii) $\quad \psi$ is non-decreasing.

Definition 2.4 ([31]) Let (X, d) be a metric space and $\mathrm{T}: \mathrm{X}$ $\rightarrow \mathrm{X}$ be a self-mapping. T is said to be an $(\alpha, \psi)-$ contractive mapping if there exists two functions $\alpha: \mathrm{X} \times \mathrm{X} \rightarrow[0, \infty)$ and $\psi \in \varphi$ such that

$$
\alpha(\mathrm{x}, \mathrm{y}) \mathrm{d}(\mathrm{Tx}, \mathrm{Ty}) \leq \psi(\boldsymbol{d}(\boldsymbol{x}, \boldsymbol{y})) \text { for all } \mathrm{x}, \mathrm{y} \in \mathrm{X} .
$$

Definition 2.5 ([31]) Let $(X, d)$ be a metric space and $\mathrm{T}: \mathrm{X}$ $\rightarrow \mathrm{X}$ and $\alpha: \mathrm{X} \times \mathrm{X} \rightarrow[0, \infty)$. T is said to be $\alpha$-admissible if

$$
\mathrm{x}, \mathrm{y} \in \mathrm{X}, \alpha(\mathrm{x}, \mathrm{y}) \geq 1 \Rightarrow \alpha(\mathrm{Tx}, \mathrm{Ty}) \geq 1 \text {. }
$$

Now we present an example of $\alpha$-admissible mappings.

Example2.6 Let $X$ be the set of all non-negative real numbers. Let us define the mapping

$$
\begin{aligned}
& \alpha: X \times X \rightarrow[\mathrm{X}, \infty) \text { by } \\
& \alpha(\mathrm{x}, \mathrm{y})= \begin{cases}2^{x-y}, & \text { if } x \geq y \\
0, & \text { if } x<y\end{cases}
\end{aligned}
$$

and define the mapping $T: X \rightarrow X$ by $T x=2^{x}$ for all $x \in$ $X$. Then $T$ is $\alpha$-admissible.

Let $\mathrm{K}$ denote all functions $\psi:[\mathrm{X}, \infty) \rightarrow$ $[\mathrm{X}, \infty)$ which satisfy the following properties: 
(i) $\quad \psi$ is non-decreasing;

(ii) $\quad \sum_{n=1}^{\infty} \psi^{n}(\boldsymbol{a})<\infty$ for each a $>0$, where $\psi^{n}$ is the nth iterate of $\xi$;

(iii)

$\psi(\mathrm{a}+\mathrm{b})=\psi(\mathrm{a})+\psi(\mathrm{b})$

Lemma $2.7[31]$ If $\psi:[\mathrm{X}, \infty) \rightarrow[\mathrm{X}, \infty)$ is a non-decreasing function, then for each $a>0$,

$$
\lim _{n \rightarrow \infty} \psi^{n}(\boldsymbol{a}) \text { implies } \psi(\mathrm{a})<\mathrm{a} \text {. }
$$

Definition 2.8 [26] Let $(X, d)$ be a metric space and $T: X$ $\rightarrow X$ be a given mapping. We say that $T$ is $(\psi, \alpha)-$ expansive mappings if there exist two functions $\psi:[\mathrm{X}$, $\infty) \rightarrow[\mathrm{X}, \infty)$ and $\alpha: X \times X \rightarrow[\mathrm{X}, \infty)$ such that $\psi(d(T x, T y)) \geq \alpha(\mathrm{x}, \mathrm{y}) \mathrm{d}(\mathrm{x}, \mathrm{y})$ for all $\mathrm{x}, \mathrm{y} \in \mathrm{X}$.

In what follows, we present the main results of Samet et al. [11].

Theorem 2.9 [31] Let $(X, d)$ be a complete metric space and $\mathrm{T}: \mathrm{X} \rightarrow \mathrm{X}$ be an $\alpha-\psi$ contractive mapping satisfying the following conditions:

(i) $\mathrm{T}$ is $\alpha$-admissible;

(ii) there exists $\mathrm{x}_{0} \in X$ such that $\alpha\left(\mathrm{x}_{0}, \mathrm{Tx}_{0}\right) \geq 1$;

(iii) $\mathrm{T}$ is continuous.

Then $\mathrm{T}$ has a fixed point, that is, there exists $\mathrm{x} \in \mathrm{X}$ such that $\mathrm{Tx}=\mathrm{x}$

Theorem 2.10 [31] Let $(X, d)$ be a complete metric space and $\mathrm{T}: \mathrm{X} \rightarrow \mathrm{X}$ be an $\alpha-\psi$ - contractive mapping satisfying the following conditions:

(i) $\quad \mathrm{T}$ is $\alpha$-admissible;

(ii) there exists $\mathrm{x}_{0} \in \mathrm{X}$ such that $\alpha\left(\mathrm{x}_{0}, \mathrm{Tx}_{0}\right) \geq 1$;

(iii) if $\left\{x_{n}\right\}$ is a sequence in $X$ such that $\alpha\left(x_{n}, x_{n+1}\right)$ $\geq 1$ for all $n$ and $x_{n} \rightarrow x \in X$ as $n \rightarrow \infty$, then $\alpha\left(x_{n}, x\right) \geq 1$ for all $n$.

Then $\mathrm{T}$ has a fixed point.

Samet et al. [31] added the following condition $(\mathrm{H})$ to the hypotheses of Theorem 2.10 and Theorem 2.10 to assure the uniqueness of the fixed point:

(H) For all $x, y \in X$, there exists $z \in X$ such that $\alpha(x$, $z) \geq 1$ and $\alpha(y, z) \geq 1$.

We introduce here a new notion of $(\psi, \alpha)$ expansive mappings as follows:

Let $\mathrm{K}$ denote the set of all functions $\psi:[0,+\infty) \rightarrow[0,+\infty)$ which satisfy the properties:

(i) $\quad \psi$ is non-decreasing ;

(ii) $\quad \sum_{i, j=1}^{\infty} b^{i} \psi^{j}(\mathrm{a})<+\infty$ for each a $>0$, where $\psi^{j}$ is the $\mathrm{j}^{\text {th }}$ iterate of $\psi$;

(iii) $\quad \psi(\mathrm{a}+\mathrm{b})=\psi(\mathrm{a})+\psi(\mathrm{b}), \forall \mathrm{a}, \mathrm{b} \in[0,+\infty)$

Lemma 2.11 [31] If $\psi:[0,+\infty) \rightarrow[0,+\infty)$ is a nondecreasing function, then for each $\mathrm{a}>0$,

$$
\lim _{n \rightarrow+\infty} \psi^{\mathrm{n}}(\mathrm{a})=0 \text { implies } \psi(\mathrm{a})<\mathrm{a} \text {. }
$$

Definition 2.12 [26] Let $(X, d)$ be a metric space and $T$ : $X \rightarrow X$ be a given mapping. We say that $T$ is an $(\psi, \alpha)-$ expansive mapping if there exist two functions $\psi \in \mathrm{K}$ and $\alpha: \mathrm{X} \times \mathrm{X} \rightarrow[0,+\infty)$ such that
(A) $\psi(d(T x, T y)) \geq \alpha(x, y) d(x, y)$

for all $\mathrm{x}, \mathrm{y} \in \mathrm{X}$.

Remark 2.13 If $\mathrm{T}: \mathrm{X} \rightarrow \mathrm{X}$ is an expansion mapping, then $\mathrm{T}$ is an $(\psi, \alpha)$-expansive mapping, where $\alpha(\mathrm{x}, \mathrm{y})=1$ for all $\mathrm{x}, \mathrm{y}$ $\in X$ and $\psi(a)=$ sa for all $\mathrm{a} \geq 0$ and some $\mathrm{s} \in[0,1)$.

Throughout this paper we shall making use of the standard notations and terminologies of nonlinear analysis.

\section{MAIN RESULTS}

Theorem 3.1 Let $(X, d)$ be a complete $b$ - metric space with constant $\mathrm{b} \geq 1$ and $\mathrm{T}: \mathrm{X} \rightarrow \mathrm{X}$ be a bijective, $(\psi, \alpha)$ - expansive mapping satisfying the following conditions:

(i) $\quad T^{-1}$ is $\alpha$-admissible;

(ii) there exists $\mathrm{x}_{0} \in \mathrm{X}$ such that $\alpha\left(x_{0}, T^{-1} x_{0}\right) \geq 1$;

(iii) $\mathrm{T}$ is continuous

Then $T$ has a fixed point, that is, there exists $z \in X$ such that $\mathrm{Tz}=\mathrm{z}$.

Proof : Let us define the sequence $\left\{\mathrm{x}_{\mathrm{n}}\right\}$ in $\mathrm{X}$ by $x_{n}=$ $\mathrm{T} x_{n+1}$, for all $\mathrm{n} \in \mathrm{N}$,

where $\mathrm{x}_{0} \in \mathrm{X}$ is such that $\alpha\left(x_{0}, T^{-1} x_{0}\right) \geq 1$. Now, if $x_{n}=$ $x_{n+1}$ for any $\mathrm{n} \in \mathrm{N}$, then from the definition $\left\{\mathrm{x}_{\mathrm{n}}\right\}$ it can be easily seen that $x_{n}$ is a fixed point of T. Hence, without loss of generality, we may assume $x_{n} \neq x_{n+1}$ for each $\mathrm{n} \in \mathrm{N}$.

It is given that $\alpha\left(x_{0}, x_{1}\right)=\alpha\left(x_{0}, T^{-1} x_{0}\right)$. Recalling that $T^{-1}$ is $\alpha$-admissible, therefore, we have

$$
\alpha\left(T^{-1} x_{0}, T^{-1} x_{1}\right)=\alpha\left(x_{0}, x_{1}\right) \geq
$$

1

Using mathematical induction, we obtain

(3.1.1) $\alpha\left(x_{n}, x_{n+1}\right) \geq 1$ for all $n \in \mathrm{N}$.

Using (3.1.1) and applying the inequality (A) with $\mathrm{x}=x_{n}$, and $\mathrm{y}=x_{n+1}$, we obtain

$$
d\left(x_{n}, x_{n+1}\right) \leq \quad \alpha\left(x_{n}, x_{n+1}\right) d\left(x_{n}, x_{n+1}\right) \leq
$$

$\psi(d(T x, T y))=\psi\left(d\left(x_{n-1}, x_{n}\right)\right)$

Therefore, by repetition of the above inequality, we have that

$$
d\left(x_{n}, x_{n+1}\right) \leq \psi^{n}\left(d\left(x_{0}, x_{1}\right)\right), \text { for all } \mathrm{n} \in \mathrm{N} .
$$

For any $\mathrm{n}>\mathrm{m} \geq 0$, we have

$\mathrm{d}\left(\mathrm{x}_{\mathrm{m}}, \mathrm{x}_{\mathrm{n}}\right) \leq \mathrm{bd}\left(\mathrm{x}_{\mathrm{m}}, \mathrm{x}_{\mathrm{m}+1}\right)+\mathrm{b}^{2} \mathrm{~d}\left(\mathrm{x}_{\mathrm{m}+1}, \mathrm{x}_{\mathrm{m}+2}\right)+\ldots+\mathrm{b}^{\mathrm{n}-\mathrm{m}} \mathrm{d}\left(\mathrm{x}_{\mathrm{n}-}\right.$ $\left.1, \mathrm{x}_{\mathrm{n}}\right)$

$$
\leq\left(b \psi^{\mathrm{m}}+\mathrm{b}^{2} \psi^{\mathrm{m}+1}+\ldots+\mathrm{b}^{\mathrm{n}-\mathrm{m}} \psi^{\mathrm{n}-1}\right) \mathrm{d}\left(\mathrm{x}_{0}, \mathrm{x}_{1}\right)
$$

From $\sum_{i, j=1}^{\infty} b^{i} \psi^{j}(\mathrm{a})<+\infty$ for each a $>0$, it follows that $\left\{x_{n}\right\}$ is a Cauchy sequence in the complete metric space $(\mathrm{X}, \mathrm{d})$. So, there exists $\mathrm{z} \in \mathrm{X}$ such that $x_{n} \rightarrow \mathrm{z}$ as $\mathrm{n} \rightarrow+\infty$. From the continuity of $T$, it follows that $x_{n}=T x_{n+1} \rightarrow T \mathrm{z}$ as $n \rightarrow+\infty$. By the uniqueness of the limit, we get $z=T z$, that is, $z$ is a fixed point of $T$. This completes the proof.

In what follows, we prove that Theorem 3.1 still holds for $\mathrm{T}$ not necessarily continuous, assuming the following condition:

(B): If $\left\{x_{n}\right\}$ is a sequence in $\mathrm{X}$ such that $\alpha\left(x_{n}, x_{n+1}\right) \geq 1$ for all $\mathrm{n}$ and $\left\{x_{n}\right\} \rightarrow \mathrm{u} \in \mathrm{X}$ as $\mathrm{n} \rightarrow+\infty$, then

(3.1.2) $\alpha\left(x_{0}, T^{-1} x_{0}\right) \geq 1$, for all $\mathrm{n}$. 
Theorem 3.2 If in Theorem 3.4 we replace the continuity of $\mathrm{T}$ by the condition (B), then the result holds true.

Proof: Following the proof of Theorem 3.1, we know that $\left\{x_{n}\right\}$ is a sequence in $X$ such that

$\mathrm{d}\left(x_{n}, x_{n+1}\right) \geq 1$ for all $\mathrm{n}$ and $\left\{x_{n}\right\} \rightarrow \mathrm{z} \in \mathrm{X}$ as $\mathrm{n} \rightarrow+\infty$. Now, from the hypothesis (3.1.2), we have

(3.2.1) $\quad \alpha\left(T^{-1} x_{n}, T^{-1} z\right) \geq 1$, for all $n \in \mathrm{N}$.

From (3.2.1), (3.1.2) and b-triangular inequality, we have

$$
\begin{aligned}
d\left(T^{-1} z, z\right) & \leq b\left(d\left(T^{-1} z, x_{n+1}\right)+d\left(x_{n+1}, z\right)\right) \\
& =\mathrm{b} \alpha\left(T^{-1} z, T^{-1} x_{n}\right) d\left(T^{-1} z, T^{-1} x_{n}\right) \\
+\mathrm{b} d\left(x_{n+1}, z\right) & \leq b \psi\left(d\left(x_{n}, z\right)+\mathrm{b} d\left(x_{n+1}, z\right)\right)
\end{aligned}
$$

Continuity of $\psi$ at $\mathrm{t}=0$ implies that $\left(\mathrm{T}^{-1} \mathrm{z}, \mathrm{z}\right)=0$ as $\mathrm{n} \rightarrow$ $+\infty$. That is, $T^{-1} \mathrm{Z}=\mathrm{z}$.

Consider, $\mathrm{Tz}=\mathrm{T}\left(\mathrm{T}^{-1} \mathrm{z}\right)=\left(\mathrm{TTT}^{-1}\right) \mathrm{z}=\mathrm{z}$. This gives an end to the proof. $\mathrm{Q}$

\section{We now present some examples in support of our results.}

Example 3.3 Let $X=[0,+\infty)$ endowed with standard metric $d(x, y)=|x-y|$ for all $x, y \in X$. Define the mappings $\mathrm{T}: \mathrm{X} \rightarrow \mathrm{X}$ and $\alpha: \mathrm{X} \times \mathrm{X} \rightarrow[0,+\infty)$ by

$\mathrm{T}(\mathrm{x})=\left\{\begin{array}{c}2 x-\frac{7}{4}, x \geq 1, \\ \frac{x}{4}, x \in[0,1)\end{array} \quad\right.$ and $\quad \alpha(\mathrm{x}, \mathrm{y})=$ $\left\{\begin{array}{l}0, \quad x, y \in[0,1), \\ \frac{x}{4}, \text { otherwise }\end{array}\right.$

Clearly, $\mathrm{T}$ is an $(\psi, \alpha)$-expansive mapping with $\psi(\mathrm{t})=\mathrm{t} / 4$ for all $\mathrm{t} \geq 0$.

In fact, for all $\mathrm{x}, \mathrm{y} \in \mathrm{X}$, we have $\frac{1}{4} \mathrm{~d}(\mathrm{Tx}, \mathrm{Ty}) \geq \alpha(\mathrm{x}, \mathrm{y}) \mathrm{d}(\mathrm{x}$, y).

Moreover, there exists $\mathrm{x}_{0} \in \mathrm{X}$ such that $\alpha\left(x_{0}, T^{-1} x_{0}\right) \geq 1$. In fact, for $x_{0}=1$, we have $\alpha\left(1, T^{-1} 1\right)=1$.

Obviously, $\mathrm{T}$ is continuous, and so it remains to show that $T^{-1}$ is $\alpha$-admissible. For this, let $\mathrm{x}, \mathrm{y} \in \mathrm{X}$ such that $\alpha(\mathrm{x}, \mathrm{y})$ $\geq 1$. This implies that $x \geq 1$ and $y \geq 1$, and by the definitions of $T^{-1}$ and $\alpha$, we have

$T^{-1} x=\frac{x}{2}+\frac{7}{8} \geq 1, T^{-1} y=\frac{y}{2}+\frac{7}{8} \geq 1$ and $\alpha\left(T^{-1} x, T^{-1} y\right)$ $=1$,

Then $T^{-1}$ is $\alpha$-admissible.

Now, all the hypotheses of Theorem 3.4 are satisfied. Consequently, $\mathrm{T}$ has a fixed point. In this example, 0 and $\frac{7}{4}$ are two fixed points of $\mathrm{T}$.

Example 3.4 Let $X=[0, \infty)$ endowed with the standard metric $d(x, y)=|x-y|$ for all $x, y \in X$. Define the mappings $\mathrm{T}: \mathrm{X} \rightarrow \mathrm{X}$ and $\alpha: \mathrm{X} \times \mathrm{X} \rightarrow[0, \infty)$ by

$\mathrm{T}(\mathrm{x})=\left\{\begin{array}{l}\sqrt{x}, \quad x \geq 1, \\ \frac{x}{4}, x \in[0,1)\end{array} \quad\right.$ and $\quad \alpha(\mathrm{x}, \mathrm{y})=$
$\left\{\begin{array}{l}0, \quad x, y \in[0,1), \\ \frac{x}{4}, \text { otherwise }\end{array}\right.$

Due to the discontinuity of $\mathrm{T}$ at 1 , Theorem 3.1 is not applicable in this case. Clearly, $\mathrm{T}$ is an $(\psi, \alpha)$-expansive mapping with $\psi(t)=t / 4$ for all $t \geq 0$. In fact, for all $\mathrm{x}, \mathrm{y} \in \mathrm{X}$, we have

$\frac{1}{4} \mathrm{~d}(\mathrm{Tx}, \mathrm{Ty}) \geq \alpha(\mathrm{x}, \mathrm{y}) \mathrm{d}(\mathrm{x}, \mathrm{y})$.

Moreover, there exists $\mathrm{x}_{0} \in \mathrm{X}$ such that $\alpha\left(\mathrm{x}_{0}, T^{-1} \mathrm{x}_{0}\right) \geq 1$. In fact, for $\mathrm{x}_{0}=1$, we have $\alpha\left(1, T^{-1} 1\right)=1$

Now, let $\mathrm{x}, \mathrm{y} \in \mathrm{X}$ such that $\alpha(\mathrm{x}, \mathrm{y}) \geq 1$.

This implies that $\mathrm{x} \geq 1, \mathrm{y} \geq 1$ and by the definition of $T^{-1}$ and $\alpha$, we have

$T^{-1} \mathrm{x}=x^{1 / 4} \geq 1, \quad T^{-1} \mathrm{y}=y^{1 / 4} \geq 1$ and $\alpha\left(T^{-1} \mathrm{x}, \quad T^{-1} \mathrm{y}\right)=1$. Then $T^{-1}$ is $\alpha$ -

admissible.

Finally, let $\left\{x_{n}\right\}$ be a sequence in $X$ such that $\alpha\left(x_{n}, x_{n+1}\right) \geq$ 1 for $\mathrm{n}$ and $\left\{\mathrm{x}_{\mathrm{n}}\right\} \rightarrow \mathrm{x} \in \mathrm{X}$ as $\mathrm{n} \rightarrow \infty$.

Since $\alpha\left(x_{n}, x_{n+1}\right) \geq 1$ for all $n$, by the definition of $\alpha$, we have $x_{n} \geq 1$ for all $n$ and $x \geq 1$. Then $\alpha\left(T^{-1} x_{n}, T^{-1} \mathrm{x}\right)=1$.

Therefore, all the required hypotheses of Theorem 3.2 are satisfied, and so $T$ has a fixed point. Here, 0 and 1 are two fixed points of $T$.

Remark 3.5 As in the previous example, the expansion mapping theorem is not applicable in this case either. To ensure the uniqueness of the fixed point in Theorem 3.1 and 3.2 we consider the condition:

(C): For all $z_{1}, z_{2} \in \mathrm{X}$, there exists $\mathrm{z} \in \mathrm{X}$ such that $\alpha\left(z_{1}, \mathrm{z}\right) \geq$ 1 and $\alpha\left(z_{2}, z\right) \geq 1$.

Theorem 3.6 Adding the condition (B) respectively to the hypotheses of Theorem 3.1 and Theorem 3.2, we get the uniqueness of the fixed point .

Proof Theorem 3.1 and 3.2, the set of fixed points is nonempty. We shall show that if $z_{1}$ and $z_{2}$ are two fixed points of $\mathrm{T}$, that is, $\mathrm{T}\left(z_{1}\right)=z_{1}$ and $\mathrm{T}\left(z_{2}\right)=z_{2}$, then $z_{1}=z_{2}$. From the condition $(C)$, there exists $z \in X$ such that (3.6.1) $\alpha\left(z_{1}, \mathrm{z}\right) \geq 1$ and $\alpha\left(z_{2}, \mathrm{z}\right) \geq 1$

Recalling the $\alpha$-admissible property of $T^{-1}$, we obtain from (3.6.1)

(3.6.2) $\alpha\left(z_{1}, T^{-1} \mathrm{z}\right) \geq 1$ and $\alpha\left(z_{2}, T^{-1} \mathrm{z}\right) \geq 1$, for all $\mathrm{n}$ $\in N$

Therefore, by repeatedly applying the $\alpha$-admissible property of $T^{-1}$, we get

(3.6.3) $\alpha\left(z_{1}, T^{-n} \mathrm{z}\right) \geq 1$ and $\alpha\left(z_{2}, T^{-n} \mathrm{z}\right) \geq 1$, for all $\mathrm{n} \in$ N..

Using the inequalities (3.2.1) and (3.6.3), we obtain $\alpha\left(z_{1}, \quad T^{-n} \mathrm{z}\right) \leq \alpha\left(z_{1}, \quad T^{-n} \mathrm{z}\right) d\left(z_{1}, \quad T^{-n} \mathrm{z}\right) \leq \psi\left(d\left(z_{1}\right.\right.$, $\left.T^{-n+1} \mathrm{z}\right)$ )

On repeating the above inequality implies we obtain $\alpha\left(z_{1}, T^{-n} \mathrm{z}\right) \leq \psi^{n}\left(d\left(z_{1}, \mathrm{z}\right)\right)$, for all $\mathrm{n} \in \mathrm{N}$.

Thus, we have $\mathrm{T}^{-\mathrm{n}_{\mathrm{Z}} \rightarrow \mathrm{z} \text { as } \mathrm{n} \rightarrow \infty}$.

Using the similar steps as above, we obtain $\mathrm{T}^{-\mathrm{n}_{\mathrm{Z}} \rightarrow z_{2}}$ as $\mathrm{n} \rightarrow \infty$.

Now, the uniqueness of the limit of $\mathrm{T}^{-\mathrm{n}_{\mathrm{Z}}}$ 
gives us $z_{1}=z_{2}$.

This completes the proof.

\section{REFERENCES}

1. Alghamdi M., Hussain N. and Salimi P., Fixed point and coupled fixed point theorems on $b$-metric- like spaces J. Inequal. Appl., 402 (2013).

2. Ali M., Kamran T. and Karapnar E.: An approach to existence of fixed points of generalized contractive multivalued mappings of integral type via admissible mapping, Abstract and Applied Analysis, vol. 2014,Article ID 141489(2014).

3. Amini-Harandi, A: Fixed point theory for quasi-contraction maps in $b$-metric spaces. Fixed Point Theory 15(2), 351358 (2014)

4. Amiri, P, Rezapour, S, Shahzad, N: Fixed points of generalized $\alpha-\psi$-contractions. Rev. R. Acad. Cienc. Exactas Fís. Nat., Ser. A Mat. 108, 519-526 (2014)

5. Aydi, H, Bota, MF, Mitrovic, S, Karapinar, E: A fixed point theorem for set-valued quasi-contractions in $b$ metric spaces. Fixed Point Theory Appl. 2012, 88 (2012)

6. Bakhtin, I. A. : The contraction principle in quasi metric spaces. In: Functional Analysis, vol. 30, pp. 26-37. Gos. Ped. Ins., Unianowsk (1989) (Russian)

7. Bota, MF, Karapinar, E, Mles, nit, e, O: Ulam-Hyers stability results for fixed point problems via $\alpha-\psi$-contractive mapping in (b)-metric space. Abstr. Appl. Anal. 2013, Article ID 825293 (2013)

8. Bota, MF, Karapinar, E: A note on some results on multivalued weakly Jungck mappings in $b$-metric space. Cent. Eur. J. Math. 11(9), 1711-1712 (2013)

9. Branciari A.: A fixed point theorem for mappings satisfying a general contractive condition of integral type, ijmms, 531536(2002).

10. Czerwik, S. : Contraction mappings in b- metric spaces, Acta Math Inf. Univ. Ostravensis, I(1993), 511.

11. Czerwik, S. Nonlinear set valued contraction mappings in b-metric spaces, Atti Sem. Mat. Fis. Univ. Modena, 46(1998), 263-276.

12. Edelstein, $M$ : An extension of Banach's contraction principle. Proc. Am. Math. Soc. 12, 7-10 (1961)

13. Hicks T. and Rhoades B.: A Banach type fixed point theorem, Math. Japon,24(1979),327-330(1979) J. Nonlinear Sci. Appl. (in press)

14. Jachymski, J: The contraction principle for mappings on a metric space with a graph. Proc. Am. Math. Soc. 136(4), 1359-1373 (2008)

15. Jovanovic $\mathrm{M}$, kadelburg $\mathrm{Z}$ and Radenovic S. : Common fixed point results in metric type spaces, Fixed Point Theory Appl, 2010:978121(2010).

16. Kadelburg, Z, Radenović, S: Pata-type common fixed point results in b-metric and b-rectangular metric spaces.
17. Kang, SM: Fixed points for expansion mappings. Math. Jpn. 38, 713-717 (1993)

18. Karapinar E.: Fixed points results for $\alpha$-admissible mapping of integral type on generalized metric spaces, Abstract and Applied Analysis, Volume 2015, Article ID 141409.

19. Karapinar, E, Samet, B: Generalized $\alpha-\psi$ contractive type mappings and related fixed point theorems with applications. Abstr. Appl. Anal. 2012, Article ID 793486 (2012)

20. Karapinar, E, Shahi, P, Tas, K: Generalized $\alpha-\psi$-contractive type mappings of integral type and related fixed point theorems. J. Inequal. Appl. 2014, 16 (2014)

21. Khan, MA, Khan, MS, Sessa, S: Some theorems on expansion mappings and their fixed points. Demonstr. Math. 19, 673-683 (1986

22. M. Jleli and B. Samet : A new generalization of the Banach contraction principle, Journal of Inequalities and Applications 2014, 2014:38.

23. M. Rahman and M. Sarwar: Dislocated quasi $b$ metric space and fixed point theorems, Electronic Journal of Mathematical Analysis and Applications Vol. 4(2), 16-24(2016).

24. M. Shah, N. Hussain : Nonlinear contractions in partially ordered quasi $b$-metric spaces. Commun. Korean Math. Soc.27(1), 117-128 (2012)

25. Pacurar, M: A fixed point result for $\varphi$-contractions on $b$ metric spaces without the boundedness assumption. Fasc. Math. 43, 127-137(2010)

26. Priya Shahi, Jatinderdeep Kaur and S.S.Bhatia : Fixed Point Theorems for $(\xi, \alpha)$ - Expansive Mappings in Complete Metric Spaces, Fixed Point Theory and Applications, 2012, 2012:157.

27. Rhoades, B.E. : A comparison of various definitions of contractive mappings, Trans. Am. Math. Soc. 226, 257-290 (1977).

28. Rus, IA: Generalized Contractions and Applications. Cluj University Press, Cluj-Napoca (2001)

29. Saluja, A.S.; Some Fixed Point Results in b(E.A.)Property of Integral Type Mappings in bMetric Spaces, International Journal of Mathematics and Computer Research (IJMCR), Volume 8, Issue 10, PP 2147-2151( 2020).

30. Samet B., Vetro C. and Vetro P.: Fixed point theorems for $\alpha-\psi$-contractive type mappings, Nonlinear analysis, vol. 75, 2154-2165(2012).

31. Samet, B, Vetro, C, Vetro, P: Fixed point theorems for $\alpha-\psi$-contractive type mappings, Nonlinear Anal. (2011). doi:10.1016/j.na.2011.10.014

32. Samet, B: Fixed points for $\alpha-\psi$ contractive mappings with an application to quadratic integral equations. Electron. J. Differ. Equ. 2014, 152 (2014)

33. Taniguchi, T: Common fixed point theorems on expansion type mappings on complete metric 
"Fixed Point Theorems for $(\psi, \alpha)$ Type Expansive Mappings in b-Metric Spaces" spaces. Math. Jpn. 34, 139-142 (1989)

34. Z. Liu, J. Li and S. Kang, Fixed point theorems of contractive mappings of integral type, Fixed Point Theory and Applications 2013, 2013:300.

35. Z. Liu, X. Li, S. Kang and S. Cho: Fixed point theorems for mappings satisfying contractive conditions of integral type and applications, Fixed Point Theory and Applications 2011, 2011:64. 